\title{
Usability test for cloud-based m-learning assistive technology for visually impaired learners in Tanzania's higher learning institutions
}

\author{
Juliana Kamaghe $^{1 *}$, Edith Luhanga ${ }^{1}$ and Michael Kisangiri ${ }^{2}$ \\ School of Information Communication Science and Engineering, at Nelson Mandela African Institution of Science \\ and Technology, Arusha Tanzania ${ }^{1}$ \\ Senior Lecturer School of Information Communication Science and Engineering, at Nelson Mandela African \\ Institution of Science and Technology, Arusha Tanzania ${ }^{2}$
}

Received: 15-July-2019; Revised: 22-August-2019; Accepted: 25-August-2019

(C)2019 Juliana Kamaghe et al. This is an open access article distributed under the Creative Commons Attribution (CC BY) License, which permits unrestricted use, distribution, and reproduction in any medium, provided the original work is properly cited.

\begin{abstract}
The advancement of learning technologies has paved the way for learners to learn at their own pace. For visually impaired learners have been relying on other learners to get information through their smart devices. The purpose of this study focuses on usability test for designing assistive technology prototypes for m-learning to be used by visually impaired learners. The research was conducted to gather user requirement in developing $m$-learning assistive technology by which its Android packet kit was installed in smart devices to enable visually impaired learners to get accessibility and usability of the mobile learning management system available. The developed m-learning assistive technology prototype provide services to visually impaired learners through smart devices. The system contains three parts; namely, user management include user authentication for higher learning institutions, learning resources, and speech synthesizer. The overall results were obtained was $78 \%$, which exceeded the standard results for usability, which is $68 \%$; this shows that mlearning assistive technology perceived the use and acceptance by the intended users (visually impaired learners).
\end{abstract}

\section{Keywords}

Learning technologies, Smart devices, M-learning, SUS, Assistive technology, Visually impaired.

\section{Introduction}

The advancement of learning technologies has paved the way for learners to learn at their own pace. For visually impaired learners have been relying on other learners to get information through their smart devices. Visually impaired traditionally relied on the assistance and kindness of others for their everyday learning activities. It was due to the lack of essential accessibility, knowledge, skills, and affords when carrying out many learning activities. It is a little bit unknown environment for visually and makes them uncomfortable to use smart devices [1]. Most of the learning system available in Tanzania does not satisfy visually impaired learners often since they have an incomplete/ poor design to accommodate them to learn resulted from system developer's failure to involve users (Visually Impaired) during the design stage, to fit with the requirements [2,3].

\footnotetext{
*Author for correspondence
}

Recently smart devices have emerged in platforms for designed an assistive technology software which is embedded in them. Users requirements and awareness of the visually impaired population have made devices manufacturers incorporate accessibility part in their devices. Also, there are third-party developers have been trying to develop assistive technologies to fit gaps for accessibility of other smart devices available [4]. Despite the above advances, assistive, or even accessible mobile phone software development is still an emerging market [5]. Consequently, most of the instructors assume learners have sight while preparing learning material and upload them in m-learning; hence it is difficult for VIL to engage themselves in self-learning using smart devices visually impaired users face some challenges when operating their mobile phones. Partially sighted users, for example, may complain about the size of the letters on the relatively small phone screens, while blind users have difficulties finding items quickly on a touch screen smart device. These encounters, though, do not seem to be an 
obstacle to smart device adopted by the visually impaired. In fact, "people with disabilities continue to choose commodity phones, even when they are aware of specialized access options." According to WHO census estimated that there are more than 285 million visually impaired people, whereby 36 million are total blinds. In Tanzania, it has been assessed that there are about 1.2 million visually impaired between age 7years to 60 years as per National Bureau of Standard statistical data whereby $64.8 \%$ are from rural areas and $35.2 \%$ from urban parts of Tanzania. However, a large number $(39.7 \%)$ of visually impaired people never attended any education and $0.5 \%$ of them have reached university level and there are all employed, and in this 2018 there were 285 visually impaired who are currently up taking different courses in the different higher learning institution in Tanzania [6].

The purpose of this study focuses on designing and developing m-learning assistive technology to be used by visually impaired learners in Tanzania and the second objective to test and validate the developed system using usability test for designing Assistive technology prototype for m-learning to be used by visually impaired learners. The research was conducted to gather user requirement in developing m-learning assistive technology by which its Android packet kit (APK) was installed in smart devices to enable visually impaired learners to get accessibility and usability of the mobile learning management system available.

The developed system has two parts mobile android application and the server-side part. The developed mobile app is intended for visually impaired learners (VIL) to enable them to navigate through the contents, choose the right course materials uploaded in the server-side, and be able to read through a speech synthesizer. The solution was to design an assistive technology, which will overcome all the challenges visually impaired faced while accessing learning contents. The server side was initially developed to allow the developer to upload learning contents and integrated with a mobile app for VIL to understand and save audio, text contents for later use. The paper presents test and validation of m-learning assistive technology conducted in two test phases; initial (preliminary) test and final usability test.

\section{Background information}

Narrated the importance of using mobile learning in Higher Learning Institutions in Tanzania when shifting to blended learning and allow learners to access learning resources anywhere [3]. Examined the accessibility by visually impaired people of the Learning Management System (LMS) Moodle available by evaluating all assistive technologies available in smart devices [7]. Examine the challenge facing visually impaired learners in accessing graphical contents in Australian HLI and found that teaching style and perceptions of teachers can hinder the accessibility [8]. Surveyed users with visual or hearing impairments about their mobile phone accessibility needs [9]. Examines the challenges facing visual disabilities to identify accessibility problems with the current mobile phone hardware [10]. Most of the smart devices provide visually impaired learners with separate screen reading software via accessibility to enable the user to navigate through touch screen the though the best a screen reading and navigation are generally expensive for Tanzanian learners. Regardless of the expansivity of devices, learners use TalkBack to help them in their devices, though it has been challenging when it comes to the accessibility of learning management systems (m-learning) of their Higher Learning institutions through their device [11]. Developers of m-learning apps considered that all learners have sight and instructors of learning materials assumed that all learners are sighted, and learning resources have text, and graphical entities without alternative text to emphasize the topic itself hence for the learner is a little bit difficult to get a description [12].

A usability test is the process whereby the product/system designed can be used by intended users to achieve its goals efficiently, effectively with user satisfaction [13]. Nevertheless, a system should not make the user contemplate above, they should since they have restricted capability rationally. The design of a usability test is viable since it requires to comprise stakeholders from the beginning of the design stage of the system and is referred to as usercentered design [14-17]. Usability test aims to make system design and development to be more interactive and usable by concentrating on the use of the system and applying human factors, usability knowledge, and procedures [18, 19]. Still, the study focuses on usability testing for the authentication of the developed mobile application systems [20].

The purpose of selecting this usability test that, it tended to see on the user requirements and recognize the system glitches from user's point of use and provided with feedback to redesign the system for an excellent performance. In testing the Mlearning 
assistive technology, the criteria visually impaired learners were asked to check and see which faults and glitch needed to be rectified. VIL was given the smart devices installed an APK for assistive technology and were asked to see workability of the system and were able to read documents, and whenever there is an image in the text, the system was able to describe what kind and content in the picture. Due to the knowledge and skills capability of using smart devices, the research had to train VIL first before going for the usability test. Different phases of the usability test plan were involved in achieving this objective as described in Figure 1 below as the preliminary test and final testing stages. The test was done by gathering stakeholders (VIL) with pretesting questions also during testing phase stakeholder were collected and trained in the usage of the platform. VILs were facilitated during the test by listening to the audio, synthesized from the document file and were able to tune the speech in the notation of voice they require. The endorsements and experimental glitches as of initial analysis used as a means for enhancement of the system in the second testing stage.

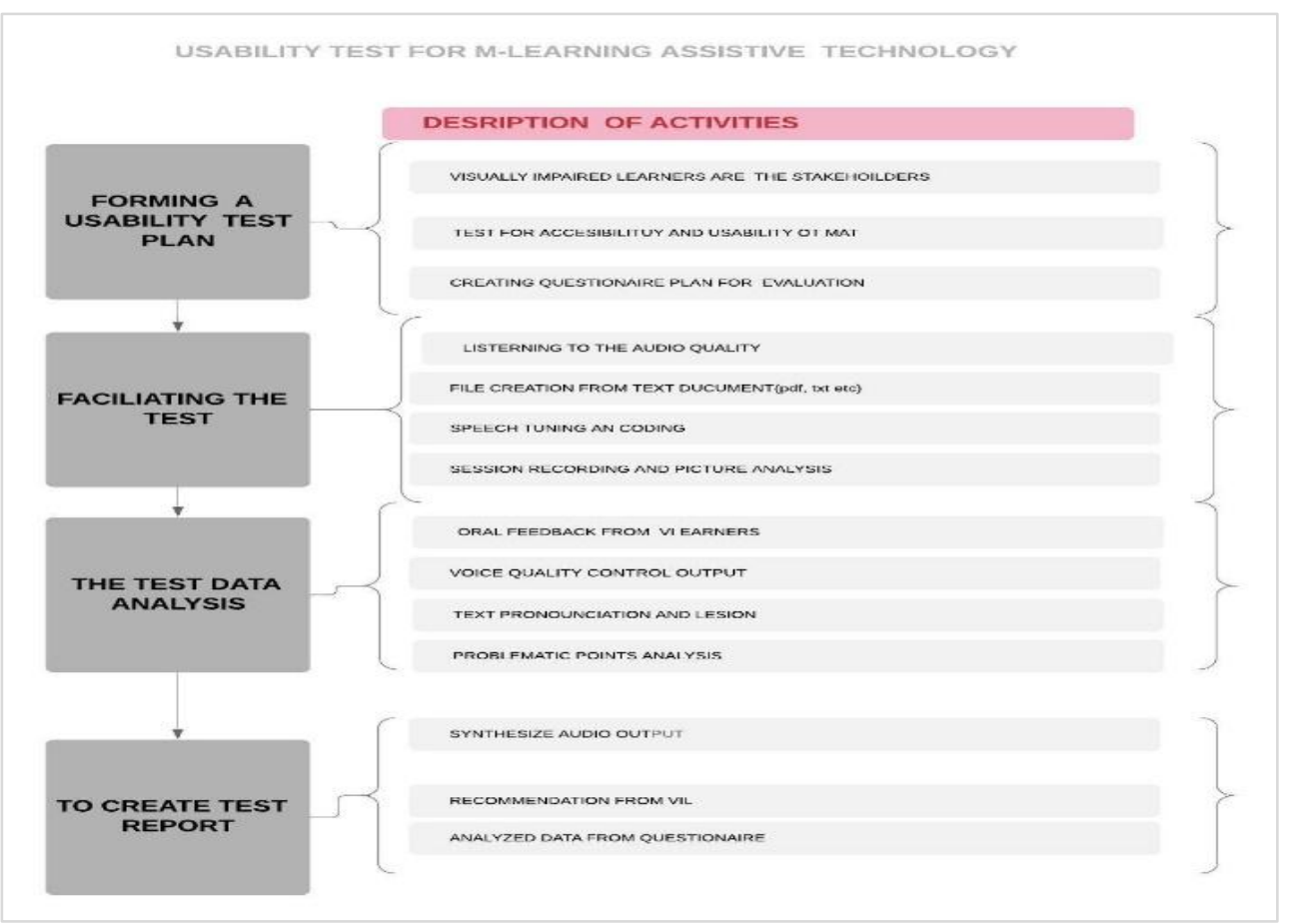

Figure 1 Usability test for m-learning assistive technology

\section{Prototype implementations for m- learning assistive technology}

The developed m-learning assistive technology prototype provide services to visually impaired learners through smart devices. The system contains three parts; namely, user management include user authentication for HLI, learning resources, and speech synthesizer. The target users of the prototype are visually impaired learners who are enrolled in higher learning institutions and needs accessibility to learning management systems through their smart devices. The system reads digital documents and provides descriptions from the picture with no alternative text, convert it into audio output and allows visually impaired learners to use fingers to 202 navigate through smart devices. The design for voice quality varies depending on the language used as depicted by [21]. For a user to get access to the mlearning platform in HLI, needs user credential/ authentication, which enables them to $\log$ into the system. The prototype allows quick browsing and editing of the documents with no error and usable with audio feedback. Also, it will enable the user to explore the touchscreen and identify the links/ navigation button required to open and read through using hand rotor. The user loads learning content from the database /HLI learning management system as shown in Figure 2 and the platform browse the text content of the document and synthesize it to speech while user browsing in the document 
prototype generates it to audio output while browsing for visually impaired learners to understand as shown in Figure 3 below. The prototype allows the user to copy documents to the clipboard and send it through mail or save in the cloud driver/ its own databases as shown in Figure 4 below also it allows the user to save the audio output for later.

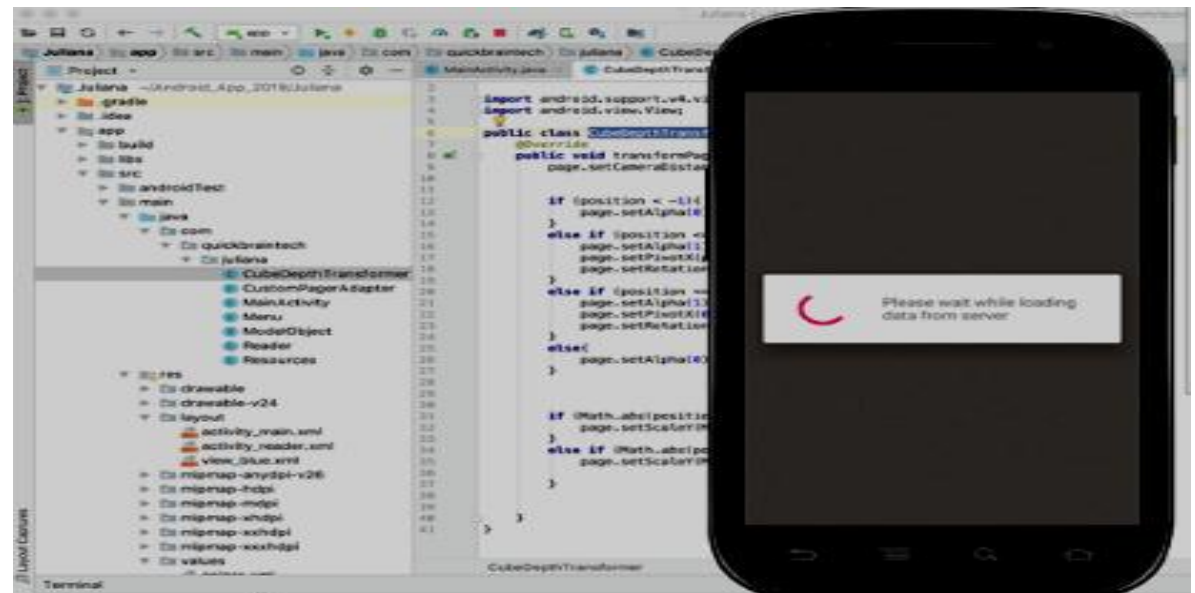

Figure 2 Prototype loading learning content from the database

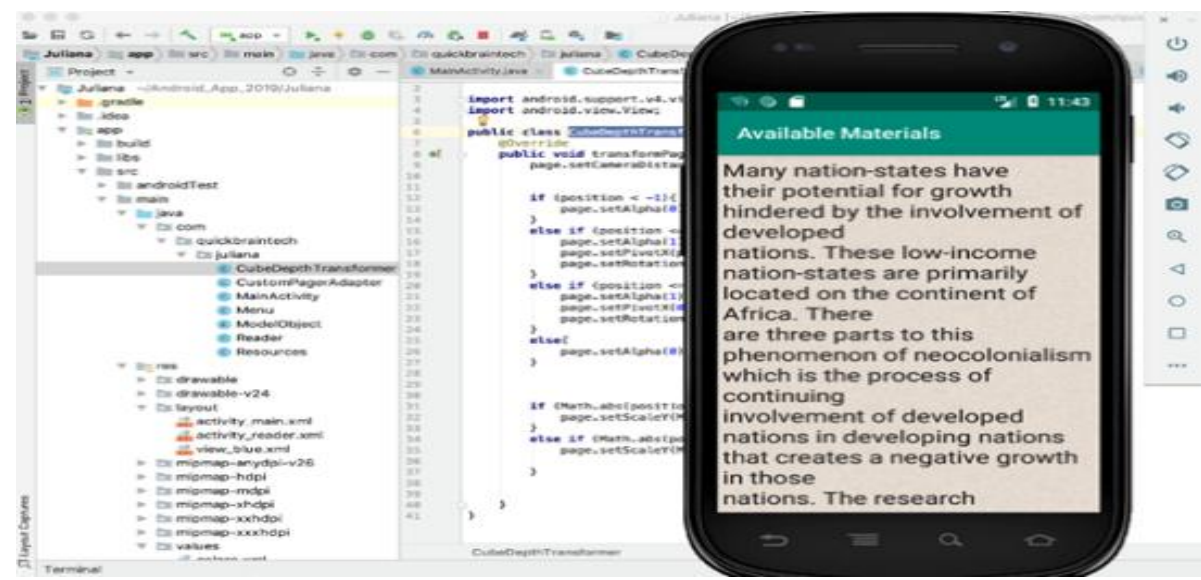

Figure 3 Audio output generated from the document

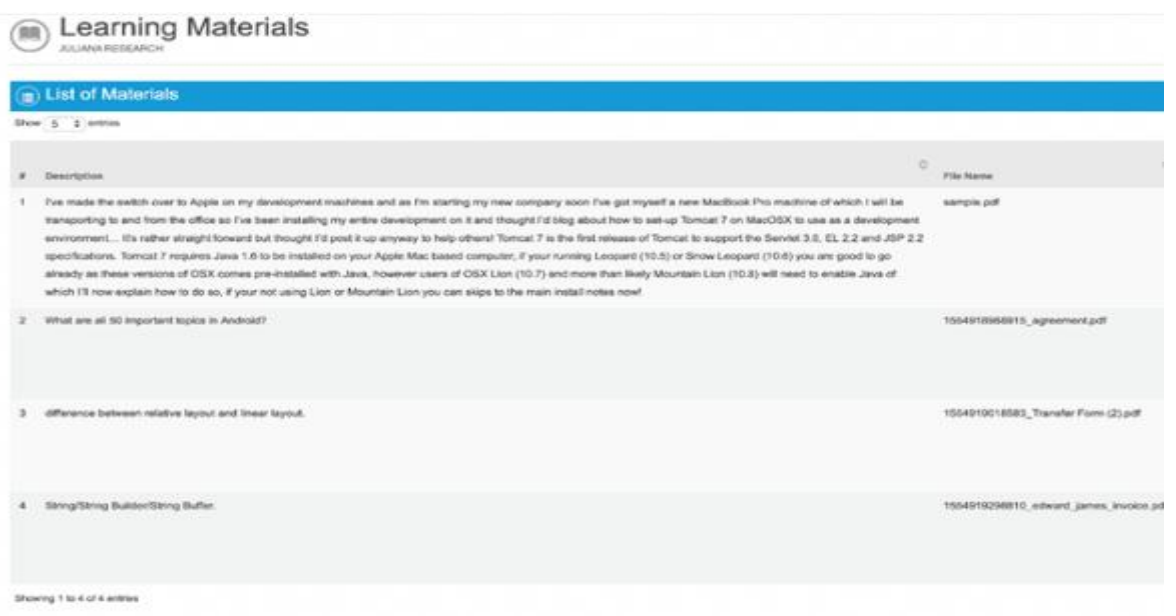

Figure 4 Prototype Learning content database 


\begin{abstract}
4.Methodology
4.1Description of the participants

The initial and final test for m-learning assistive technology involves only one group of (visually impaired learners). A total number of 7 participants were included in each phase, and participants were from The Open University of Tanzania, labs were used during the testing phase. Each participant was provided with a Techno Camon smartphone installed with Android version 9.1 and was given pre-training knowledge and skills in the usage of smart devices. And the final test phase of voice quality was tested with speech analyzer where each user listened to the audio and gave the comments and recommendations. 4.1.1Testing phases for m-learning assistive technology To measure the usability of m-learning assistive technology, the questionnaire approach was used and was responded before and after the test to make sure that the design fits with user requirements. The foremost objective of the initial test to access the usability of the system and follow up on the user comments while using and work on the recommendations given by Visually Impaired Learners. The final test stage was to analyze the design and development phase using Voxal speech analyzer 3.0. The choice of speech analyzer is to increase the quality of the audio output by considering tonation, punctuations, and pronunciation of each word for easier understandability.
\end{abstract}

The thorough testing was based on the two vital requirements, a more accessible user interface, audio output quality parameter. After, initial training on the usage and accessibility navigation on smart devices, participants are expected to learn how to navigate through the application and Login to request authentication to his/her HLI, and if she/he doesn't have Login credential the user will be able to navigate through learning materials available in the system web server. Browsing and opening documents available expected to be done in 10 minutes, reading through while synthesizing with audio output in 8 minutes. Participants are expected to be able to download and save learning contents for later. Also, participants required to go through voice features to quantify the pronunciation, tonation, and sound quality for audio output parameters for 5 minutes. After testing and evaluation of the application, participants are required to answer user.

\subsection{Initial testing of the system}

The assessment was done using after Techno Camon smart device installed an android version 9.0 app. The results of system testing scale show that the usability scale reached 68 regardless of the user problems arises, and comments and feedback were collected to raise the usability and accessibility from stakeholders. The primary purpose of the preliminary test is to answer and see what are errors and glitches observe, and user comments and feedback arise during testing and enabled the developer to recollect them.

\subsection{Explanation of initial test and final test participants}

The participants were seven visually impaired learners from the Open University of Tanzania, where we're currently studying different programs whereby 3 of there were total blinds, and 4 had lower vision who also needs assistance from others. The assortment of participants was based on the smart device's usage knowledge and skills capabilities. The first group was four visual impaired who were using dummy phones and, never used smart devices. The second group of 3 visually impaired had smart devices and use them for communications purposes have been using it in less than a year. Participants were age between 23-35, and all are employed in public services around the country and uses braille documents and audio CDs for studying purposes.

\section{Results and discussion}

\subsection{Results from the initial test}

All seven participants understood the operation and navigation modality of the system designed and were satisfied with the current system of managing learning contents through assistive technology. They argued that by using m-learning assistive technology will simplify studying life in their higher learning institutions. The test was based on two user requirements, namely as voice quality, and more accessible user interface and recommendations were as follows the use of user dropdown menu to reduce over browsing example, while searching for learning contents there should be a menu for selecting materials instead of a user typing through. Also, the system should have visible links to the articles, notes, forms, and others make the interface more accessible. Additionally, adding links to higher learning institutions websites so as learners can be able to read and get information on their HLI through the platform. Lastly, the system should be user-friendly and ready to switch language through text and be able to adjust the audio output volume while reading through the document. From the results from the questionnaire, it was observed that four out of seven participants were not fully satisfied with some of the 
system workability and they recommend on the changes for a system to fit their user requirements.

\subsection{Results from the final test of the m-learning assistive technology}

The recommendation from the initial test was executed, and the last revised system was tested with the same participants from the initial test. During final testing, participants were able to analyze the system workability from different parameters, namely as unaffectedness, responsiveness, numerous language switching, text lesion, and interoperability. To assess the quality of the output voice (speech) right to be perceived resulted from the development system, it was approved by visually impaired participants. The voice quality was tested based on the above parameters and execution, individual listening test acceptable results were attained from the test. The result shows that single spatial sound if combined with sensitive speech, make speech more normal and motivating. Based on input, text reading observed from learning resources, databases the pronunciation and tonation of words; the graphs were plotted, which are shown in Figures 2-6 below. Each participant was required to provide a mean opinion score in each parameter in which it was from 0-5 whereby 5 is the maximum score, and 0 was a minimum score. The mean opinion score (MOS) was on the output speech quality and divided as follows 0 means unsatisfied; one means poor, two means fair, three means good, four means very good and 5 Excellent. The primary parameter to assess the was unaffected (how much audio, speech from smart device's assistive technology relate to the human voice?) of the words and the mean score obtained was 4.0/5.0, signifies that the output speech was associated with the human voice. Also, the second test was based on responsiveness (how much visually impaired learners have responded, and assistive technology recognizes the alternative text for picture correctly), the results obtained are plotted in Figure 2 below, and the average score was 3.8/5 for accurate text description for images. The third parameter was the numerous language switching (that signifies how much the system can recognize languages in text and switch) when the document was reading, and output speech was played, and average results from participants were 4.4/5 as shown in Figure 4 below. The fourth parameter was text lesion how much the user understands the text read by the system in terms of melody, rhythms, tonation, and the average result was 4.2/5, as shown in Figure 5. As shown in the figure below. Lastly was interoperability (can system be integrated with learning management system available in their HLI) of the system from the users by were by the user were given smart device and the user with assistive technologies the score was higher 4.7/5 shown in Figure 6 compared to other and mostly user was delighted with the system at large. The system usability score test contained ten standard questions statement with all seven responders from seven participants.

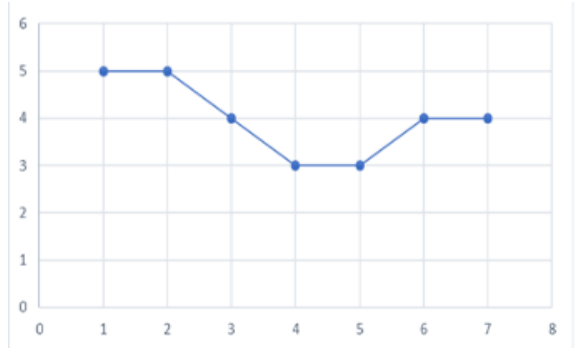

Figure 5 MOS for unaffectedness

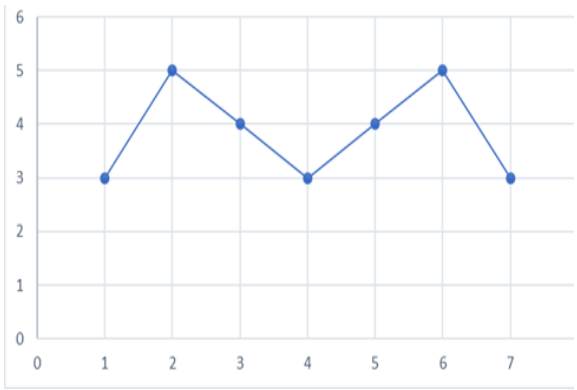

Figure 6 MOS for responsiveness

The overall results were obtained was $78 \%$, which exceeded the initial results for usability, which is $73 \%$; this shows that m-learning assistive technology perceived the use and acceptance by the intended users (visually impaired learners).

\subsection{System user satisfaction results}

Also, in SUS, the usefulness of the system and user satisfaction were measured during testing, and observation was done on the task given to each user. Task completed was measured concerning time to complete each task and participant were asked to rate their satisfaction, and the system usefulness in the scale of $0-5$ whereby 0 is lower and five is the highest satisfactory as shown in the Table 1 below. 
Juliana Kamaghe et al.

Table 1 User satisfaction for each user

\begin{tabular}{|c|c|c|c|c|}
\hline Participants & $\begin{array}{l}\text { No. of task completed } \\
\text { (of 7) }\end{array}$ & $\begin{array}{l}\text { (A)User satisfaction } \\
(0-5)\end{array}$ & $\begin{array}{l}\text { (B) System usefulness } \\
(0-5)\end{array}$ & $\begin{array}{l}\text { Average } \\
\text { A\&B }\end{array}$ \\
\hline 1. & 4 & 4.5 & 4.5 & 4.50 \\
\hline 2. & 3 & 3.9 & 4.0 & 3.95 \\
\hline 3. & 7 & 4.6 & 4.7 & 4.65 \\
\hline 4. & 6 & 4.0 & 4.1 & 4.05 \\
\hline 5. & 5 & 4.0 & 4.0 & 4.0 \\
\hline 6. & 6 & 3.7 & 4.3 & 4.0 \\
\hline 7. & 3 & 4.3 & 3.9 & 4.1 \\
\hline
\end{tabular}

Users were able to complete tasks that were given, but not on time for most users no prior knowledge on how smart devices work. After task completion, users were asked to fill the user satisfaction form in the scale of 5 on the platform satisfy their need for assistive technology and the overall results were 4.3. This indicates that participants were satisfied with the system and were able to see the usefulness of the mlearning assistive technology in their daily studies in the higher learning institution. The results from the initial test were questionnaires were different form final test done whereby in the final analysis, the performance in the testing session was improved, and app assessment of user performance with voice speech analyzer was functional. The validation test phase of m-learning assistive technology has been a success as the SUS score exceeded the score limit as supported by [22]. Mean opinion score proves that the need for assistive technology for visually impaired in Tanzania in higher since they are facing challenges while studying their courses in higher learning institutions. M-learning assistive technology will be beneficial for HLI and Visually Impaired learners since learners will be able to participate in learning at their own pace.

\section{Conclusion}

The contemporary study explores developed mlearning assistive technology for visually impaired has been a success with evidently increasing SUS from initial test to final testing of the system. Adoption of the order by visually impaired learners in higher learning institutions in Tanzania will pave the way for others to enroll and study in their own pace with their smart device to access learning materials in LMS. System acceptability from participants indicates that visually impaired learners face many challenges while studying, and they need to be addressed an provided with solution from their HLI. The system will help HLI in making sure that visually impaired who are enrolled are provided all, the necessary needs to be able to access the learning management system through assistive technology in their smart device. In future work, other user groups 206 could be added, such as visually impaired instructors who may have quite swerving insights compare to students. The limitation of this study is that there was no enough time for stakeholders and the HLI were not eager to integrate this platform to their learning management system available.

\section{Acknowledgment}

The authors acknowledge DAAD-German and African Development Bank (AFDB) for funding this research and anonymous reviewers for their contribution.

\section{Conflicts of interest}

The authors have no conflicts of interest to declare.

\section{References}

[1] Szpiro SF, Hashash S, Zhao Y, Azenkot S. How people with low vision access computing devices: Understanding challenges and opportunities. In proceedings of the international ACM SIGACCESS conference on computers and accessibility 2016 (pp. 171-80). ACM.

[2] Kim HK, Han SH, Park J, Park J. The interaction experiences of visually impaired people with assistive technology: a case study of smartphones. International Journal of Industrial Ergonomics. 2016; 55:22-33.

[3] Shemahonge R, Mtebe J. Using a mobile application to support students in blended distance courses: a case of Mzumbe University in Tanzania. International Journal of Education and Development using ICT. 2018; 14(3).

[4] Singhal R, Singhal A, Bhatnagar M, Malhotra N. Design of an audio repository for blind and visually impaired: a case study. In advanced computing and communication technologies 2019 (pp. 77-85). Springer, Singapore.

[5] Pal J, Viswanathan A, Chandra P, Nazareth A, Kameswaran V, Subramonyam H, et al. Agency in assistive technology adoption: visual impairment and smartphone use in Bangalore. In proceedings of the CHI conference on human factors in computing systems 2017 (pp. 5929-40). ACM.

[6] Turk MA. World report on disability: what are the implications for the US? Disability and Health Journal. 2012; 5(3):127-8.

[7] Armano T, Borsero M, Capietto A, Murru N, Panzarea A, Ruighi A. On the accessibility of Moodle 2 by visually impaired users, with a focus on mathematical 
content. Universal Access in the Information Society. 2018; 17(4):865-74.

[8] Butler M, Holloway L, Marriott K, Goncu C. Understanding the graphical challenges faced by vision-impaired students in Australian universities. Higher Education Research \& Development. 2017; 36(1):59-72.

[9] Hakobyan L, Lumsden J, O'Sullivan D, Bartlett H. Mobile assistive technologies for the visually impaired. Survey of ophthalmology. 2013; 58(6):51328.

[10] Kumar S, Sanaman G. Web challenges faced by blind and vision impaired users in libraries of Delhi: an Indian scenario. The Electronic Library. 2015; 33(2):242-57.

[11] Spagnol S, Csapó Á, Konstantinidis EI, Kalimeri K. Mobile assistive technologies. Wireless Communications and Mobile Computing. 2018.

[12] Sharma KD. Ensuring quality by utilizing ICT for reforms in management education through ODL in India. Asian Journal of Distance Education. 2018; 13(2):157-66.

[13] Bartolotta J, Bourelle T, Newmark J. Revising the online classroom: usability testing for training online technical communication instructors. Technical Communication Quarterly. 2017; 26(3):287-99.

[14] Yates R. Web site accessibility and usability: towards more functional sites for all. Campus-wide Information systems. 2005; 22(4):180-8.

[15] Takagi H, Asakawa C, Fukuda K, Maeda J. Accessibility designer: visualizing usability for the blind. In ACM SIGACCESS accessibility and computing 2004 (pp. 177-84). ACM.

[16] D'Atri E, Medaglia CM, Serbanati A, Ceipidor UB, Panizzi E, D'Atri A. A system to aid blind people in the mobility: a usability test and its results. In second international conference on systems 2007 (pp. 35-5). IEEE.

[17] Hassan HM, Galal-Edeen GH. From usability to user experience. In international conference on intelligent informatics and biomedical sciences 2017 (pp. 21622). IEEE.

[18] Ferati M, Raufi B, Kurti A, Vogel B. Accessibility requirements for blind and visually impaired in a regional context: an exploratory study. In international workshop on usability and accessibility focused requirements engineering 2014 (pp. 13-16). IEEE.

[19] Wattenberg T. Beyond legal compliance: communities of advocacy that support accessible online learning. The Internet and Higher Education. 2004; 7(2):123-39.

[20] Harrati N, Bouchrika I, Tari A, Ladjailia A. Exploring user satisfaction for e-learning systems via usagebased metrics and system usability scale analysis. Computers in Human Behavior. 2016; 61:463-71.
[21] Christian JM, Graff P, Nakatsu CA, Hockey BA, inventors; Intel Corp, assignee. Systems and methods for providing non-lexical cues in synthesized speech. United States patent US 9,542,929. 2017.

[22] Zaied AN, Hassan MM, Mohamed IS. Applying website usability testing techniques to promote Eservices. Advances in Computer Science: An International Journal. 2015; 4(5):54-60.

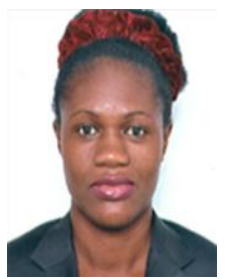

Juliana S. Kamaghe is a Ph.D. student in Information Communication Science and Engineering, Specializing Electronics and Telecommunications Engineering at Nelson Mandela African Institution of Science and Technology, Arusha Tanzania. Currently, she is working with The Open University of Tanzania as Assistant Lecturer in Information and Communication Technology Department since 2010. She graduated her MSc in Electronics and Telecommunication Engineering from Institute Superieur D'Electronique De Paris. Paris, France in 2012 and B.Eng. Electronics and Telecommunication Engineering from Dar es Salaam Institute of Technology in 2007. Her area of interest are Mlearning, E-learning, E-commerce, Wireless Sensors Networks, Value-added Services, Machine Learning, and STEM education.

Email:kamaghej@nm-aist.ac.tz

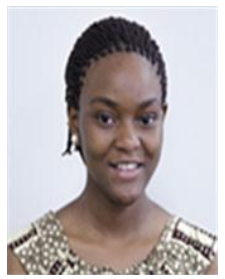

Edith Luhanga received her $\mathrm{PhD}$ in Information Science (focusing on ubiquitous computing applications) from the Nara Institute of Science and Technology in 2018. She also holds an MSc in Advanced Computing Science and a BEng (Hons) in Electronic and Computer Engineering from the University of Nottingham. She is a lecturer at the Nelson Mandela African Institution of Science and Technology (NM-AIST) in Arusha, Tanzania. Her research interests include Human-Computer Interactions and User-Centered Development of mobile and Internet-of-Things (IoT) applications for Health, Education, Social Development, and IoT Privacy and Security solutions.

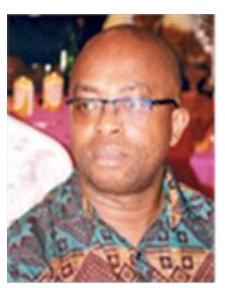

Dr. Michael Kisangiri Francis Michael has been working with NM-AIST as a lecturer then Senior lecturer since December 2011. Before joining NM-AIST he worked with Dar-es-Salaam Institute of Technology DIT. $\mathrm{He}$ is a Ph.D. holder in the field of Telecommunications which he graduated from the Wroclaw University of Technology - Poland. He has successfully managed dozens of researches in the level of MSc degree and several in the level of Ph.D. degree. He possesses good knowledge in Artificial Intelligence, Antenna Design, and Wireless Communication Systems. His research interest is in Machine Learning, IoT and MIMO Antenna. 